\title{
ВОЗМОЖНОСТЬ ИСПОЛЬЗОВАНИЯ ДАННЫХ ДИСТАНЦИОННОГО ЗОНДИРОВАНИЯ ПРИ МОНИТОРИНГЕ ВОДНЫХ ОБЪЕКТОВ
}

\section{Наталья Сергеевна Решетило}

Сибирский государственный университет геосистем и технологий, 630108, Россия, г. Новосибирск, ул. Плахотного, 10, обучающийся, тел. (999)463-26-85, e-mail: natalya.reshetilo@mail.ru

\section{Елена Павловна Хлебникова}

Сибирский государственный университет геосистем и технологий, 630108, Россия, г. Новосибирск, ул. Плахотного, 10, доцент кафедры фотограмметрии и дистанционного зондирования, тел. (913)901-94-58, e-mail: e.p.hlebnikova@sgugit.ru

В статье рассмотрены первостепенные задачи мониторинга водных объектов, цели, возможности использования данных дистанционного зондирования с применением программного комплекса Erdas Imagine 2015. Показано как с помощью данных дистанционного зондирования можно получить достоверную информацию о состоянии водных объектов, выявить и спрогнозировать неблагоприятные экологические явления, а также извлечь полезную информацию.

Ключевые слова: дистанционное зондирование, мониторинг водных объектов, разновременные космические снимки, наводнение, стихийное бедствие, Sentinel-2, Erdas Imagine

\section{POSSIBILITY OF USING REMOTE SENSING DATA IN MONITORING WATER OBJECTS}

\section{Natalya S. Reshetilo}

Siberian State University of Geosystems and Technologies, 10, Plakhotnogo St., Novosibirsk, 630108, Russia, Student, phone: (999)463-26-85, e-mail: natalya.reshetilo@mail.ru

\section{Elena P. Khlebnikova}

Siberian State University of Geosystems and Technologies, 10, Plakhotnogo St., Novosibirsk, 630108, Russia, Associate Professor, Department of Photogrammetry and Remote Sensing, phone: (913)901-94-58, e-mail: e.p.hlebnikova@sgugit.ru

The article discusses the primary tasks of monitoring water bodies, the goals, the possibility of using remote sensing data using the Erdas Imagine 2015 software package. It is shown how, using remote sensing data, one can obtain reliable information about the state of water bodies, identify and predict unfavorable environmental phenomena, and extract useful information.

Keywords: remote sensing, water monitoring, different-time space imagery, flood, natural disaster, Sentinel-2, Erdas Imagine

\section{Введение}

Мониторинг водных объектов - не прекращаемое или постоянное наблюдение за состоянием водных объектов, контроль комплекса их гидрологических и иных характеристик, а также их пространственных и временных изменений [8].

Тема данной статьи актуальна тем, что мониторинг водных объектов на данный период времени важен за счет того, что включает в себя определенный набор 
систематических наблюдений за гидрогеологическими, микробиологическими, токсикологическими и другими показателями их состояния. С его помощью можно осуществлять сбор, обработку и передачу информации, чтобы своевременно выделить отрицательные процессы, оценить и спрогнозировать их развитие, дать необходимые рекомендации по устранению последствий, которые могут принести вред; а также определить уровень эффективности проводимых водохозяйственных действий $[3,10]$. Помимо этого мониторинг водных объектов необходим организациям, занимающимся обслуживанием систем водохозяйствования и гидротехнических сооружений, а услуга «своевременное получение информации о паводках и наводнениях» актуальна для спасательных служб, одна из них - МЧС $[13,17]$.

Целью работы является оценка возможности использования данных дистанционного зондирования при мониторинге водных объектов.

Дистанционное зондирование (далее - ДЗ) - процесс, на основе которого добывается информация о поверхности Земли, объектах, атмосфере, верхнем слое земной коры, океане, с учетом бесконтактного метода, при использовании которого прибор регистрации удален от исследуемого объекта на внушительное расстояние $[2,11,20]$. Систематическое ДЗ дает возможность отследить то, как меняется экологическая система с учетом воздействия природного и человеческого фактора [14].

Конкретным объектом для использования данных дистанционного зондирования при мониторинге водных объектов в данной статье является Иркутская область. В конце июня 2019 года в Иркутской области случилось затопление, в котором пострадали люди. Фактором, выступившим главным источником затопления явились сильные дожди, совпавшие с таянием снега в горах Восточного Саяна, что привели к подъему рек $[1,7]$. Во время паводка наивысший уровень реки Ия в городе Тулун поднялся до 14 м (достиг пика), притом, что ее максимальная граница 700 см. Наблюдалось две волны затопления. Более подробная характеристика каждой представлена в табл. 1 и 2.

Таблий 1

Первая волна затопления Иркутской области

\begin{tabular}{|c|c|}
\hline $\begin{array}{c}\text { Дата первой } \\
\text { волны затопления }\end{array}$ & События первой волны затопления \\
\hline 25 июня & Началось повышение уровня воды в притоках реки Ангара. \\
\hline 29 июня & $\begin{array}{l}\text { На 01:00, подтоплен } 31 \text { населённый пункт в четырёх муниципальных } \\
\text { районах - Нижнеудинском, Тайшетском, Тулунском и Чунском. } \\
\text { К полудню максимальный подъём уровня воды на реке Ия в районе го- } \\
\text { рода Тулун составил } 13,8 \text { м. }\end{array}$ \\
\hline 30 июня & $\begin{array}{l}\text { Погибли пять человек, в больницы попали больше ста. Под водой ока- } \\
\text { зались } 4 \text { тысячи домов в } 31 \text { населённом пункте. }\end{array}$ \\
\hline 1-2 июля & $\begin{array}{l}\text { Началось снижение уровня воды во всех зонах подтопления. Начались } \\
\text { работы по ликвидации последствий паводка. Начаты работы по восста- } \\
\text { новлению электроснабжения. }\end{array}$ \\
\hline
\end{tabular}


По прошествии первой волны уровень воды в реке Ия упал до 500 см, с учетом того, что самой высокой отметкой для текущего места считается 700 см.

Данные по второй волне затопления Иркутской области представлены в табл. 2.

Вторая волна затопления Иркутской области

Таблиия 2

\begin{tabular}{|l|l|}
\hline $\begin{array}{c}\text { Дата второй } \\
\text { волны затопле- } \\
\text { ния }\end{array}$ & \multicolumn{1}{|c|}{ События второй волны затопления } \\
\hline 27 июля & $\begin{array}{l}\text { Во второй половине 27 июля в реке Ия начался интенсивный рост } \\
\text { уровня воды. Если в 8:00 уровень реки составлял 490 см, то в 14:00 того } \\
\text { же дня он составил 518 см. }\end{array}$ \\
\hline 29 июля & $\begin{array}{l}\text { Было опубликовано официальное предупреждение о том, что 29-30 } \\
\text { июля ожидается повышение уровня воды на реках Ия, Иркут, Ока и ее } \\
\text { притоках. На р. Ия в районе г. Тулун до отметок 950-1050 см, при кри- } \\
\text { тической отметке 700 см. } \\
\text { В конце дня уровень реки Ия составил 864 см. }\end{array}$ \\
\hline 31 июля & $\begin{array}{l}\text { Уровень воды в реке Ия составил 1082 см (на 382 см выше критического } \\
\text { уровня). }\end{array}$ \\
\hline 4 августа & $\begin{array}{l}\text { Ситуация с подтоплением в Иркутской области начала стабилизиро- } \\
\text { ваться. Уровень воды в реке Ия снизился и находится ниже критической } \\
\text { отметки. }\end{array}$ \\
\hline
\end{tabular}

Последствия наводнения Иркутской области (г. Тулун) представлены на рис. 1.

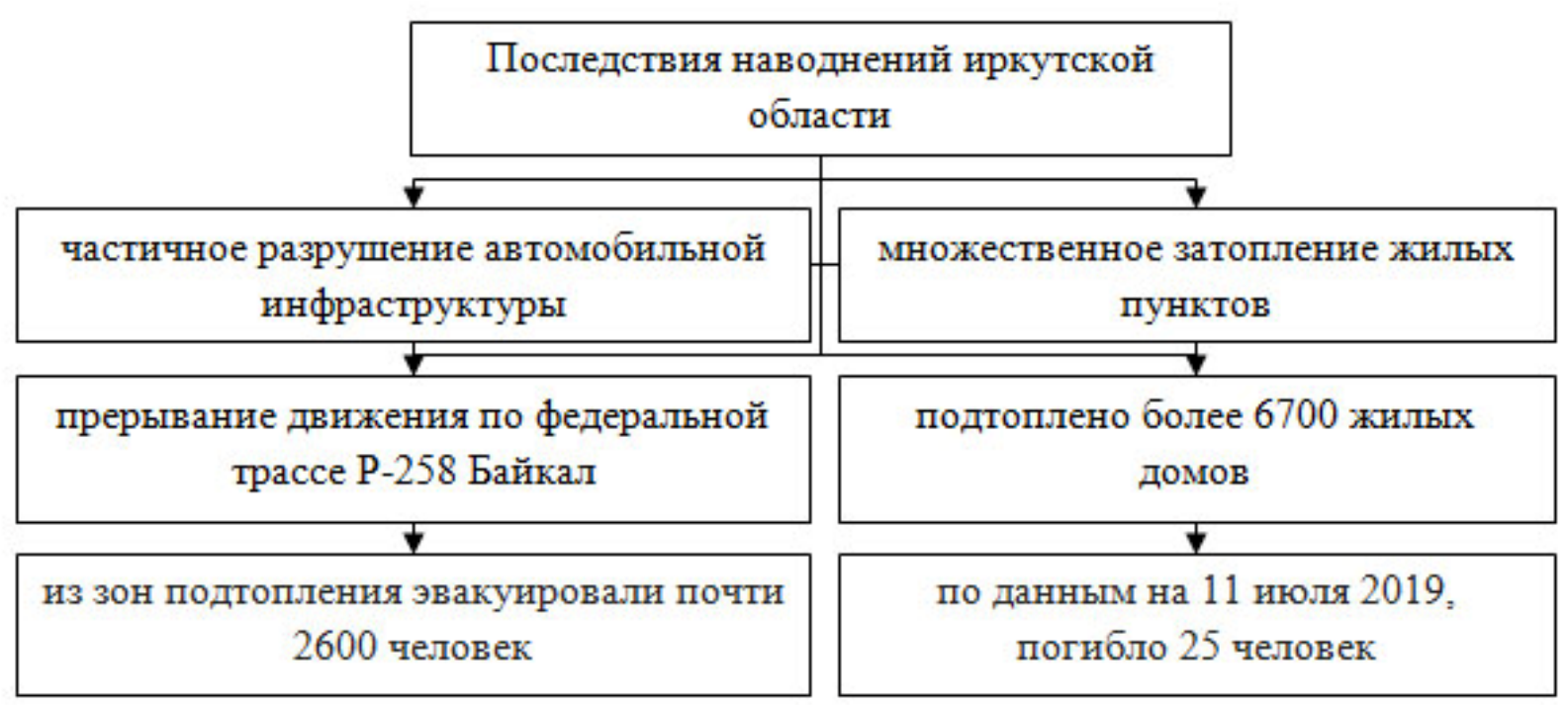

Рис. 1. Схема последствий наводнения Иркутской области

Трасса Р-258 Байкал является единственной автодорогой, которая связывает центр России с Сибирью и Дальним Востоком (Москва-Владивосток) $[5,9]$.

Помимо подтопления, некоторые дома были снесены полностью. 
Оценка ущерба от наводнения в иркутской области выведена на рис. 2.

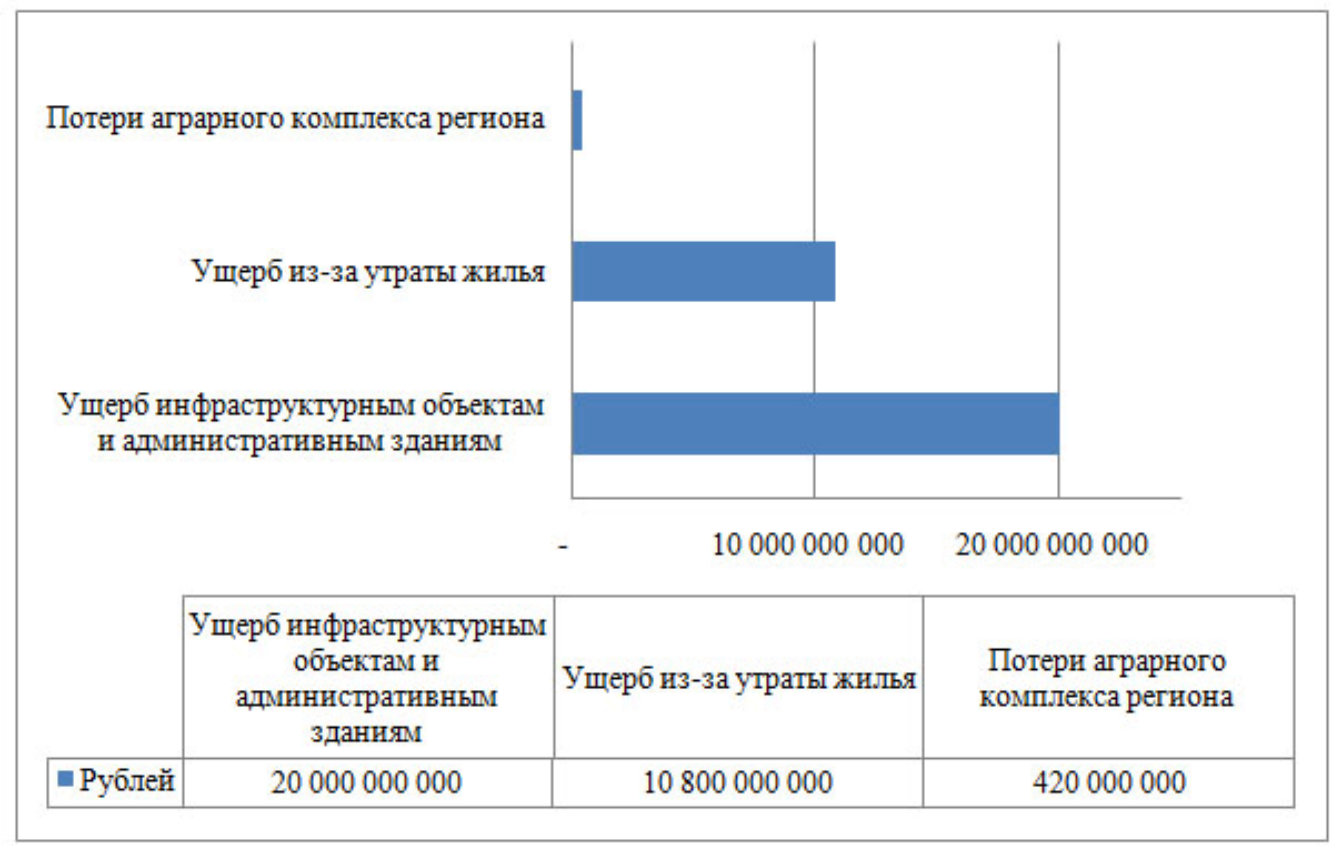

Рис. 2. График оценки ущерба от наводнений в Иркутской области

Как видно, больше всего впоследствии наводнения понесли ущерб инфраструктурные объекты и административные здания - 20 млрд.рублей; вслед за ним ущерб среднего масштаба пришелся на утрату жилья - 10800000000 рублей; а следом аграрный комплекс региона - 420000000 рублей [6].

Таким образом, наводнение - масштабное стихийное бедствие, хоть и временное, но последствия после него значительные. Среди таких - разрушение почвенных земель, материальные затраты на восстановление разрушенных домов или других сооружений, которые подверглись затоплению и др. Наводнение в Иркутской области было вызвано обильными осадками, которые длились продолжительное время. Таким образом, Иркутская область подверглась двум волнам затопления, которые пришлись на конец июня (1 волна), и середину июля (2 волна) 2019 года. Из всех городов больше всего подвергся затоплению город Тулун.

\section{Методы и материаль}

Учитывая проблемы, поставленную цель и задачи, необходимыми материалами и методами решения выступил программный продукт Erdas Imagine 2015 , и космические снимки, полученные космической съемочной системой Sentinel-2.

Erdas Imagine 2015 - программное обеспечение, с помощью которого можно обрабатывать данные ДЗ с целью анализа и интерпретации изображений. Прежде всего, данная программа это один из лучших инструментов по работе с растровыми 
данными, с помощью которой можно проводить пространственное моделирование, работать с двухмерными и трехмерными изображениями $[15,16]$.

Sentinel-2 - это пара спутников, которые были запущены Европейским космическим агентством в 2015 году. Они оснащены оптико-электронным мультиспектральным сенсором для проведения съемок, имеющих пространственное разрешение от 10 до 60 метров в видимой, ближней инфракрасной и коротковолновой инфракрасной зонах спектра, которые включают в себя 13 каналов $[4,12,18,19]$.

\section{Результатьи}

На первом этапе работы были получены снимки Sentinel-2, на разные даты, а именно на 19, 29 июня; 1, 4, 31 июля и 5 августа 2019 г.

Комплект поставки снимков включает три варианта пространственного разрешения (10 м, 20 м, 60 м).

На рис. 3 представлены варианты пространственного разрешения на примере снимка от 19 июня 2019 г.

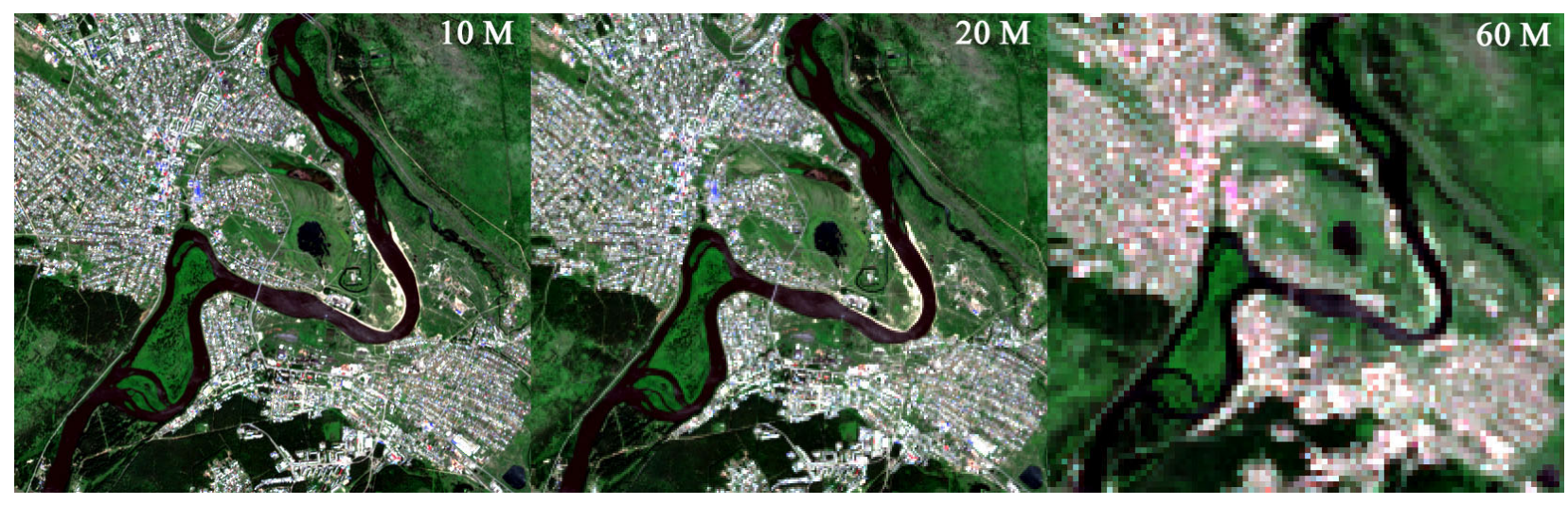

Рис. 3. Снимок на 19 июня с пространственными разрешениями

$$
10 \mathrm{M}, 20 \mathrm{M}, 60 \mathrm{M}
$$

Как правило, и как видно на рис. 3, лучшим пространственным разрешением считается 10 м, однако, в нашем случае для мониторинга водного объекта целесообразно использовать разрешение 20 м, так как на снимке достаточно хорошо видна зона затопления, изображение не загрублено, как при разрешении 60 м, и не слишком детально, как при разрешении 10 м.

Для того чтобы провести дальнейший анализ снимков, многоканальные изображения «сшивались» в программном продукте Erdas Imagine 2015.

После сшивки всех снимков, была вырезана их часть, соответствующая области интереса для данного исследования.

В результате «сшивки», обрезки области интереса, а также выбора необходимых каналов, были получены исходные материалы, фрагменты снимков на все интересующие даты, которые показаны на рис. 4. 


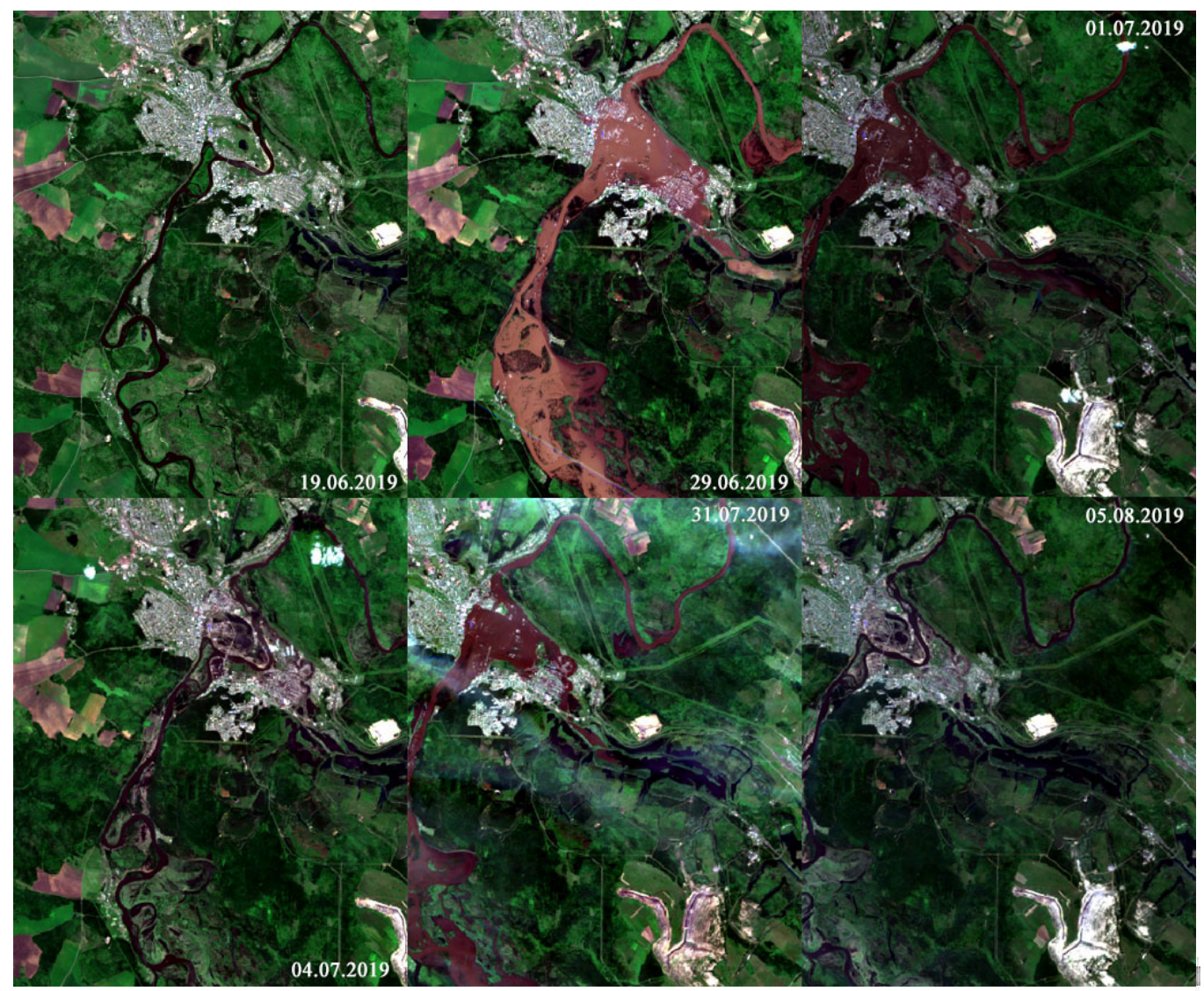

Рис. 4. Результат сшивки, обрезки области интереса и выбор каналов для дальнейшего анализа на каждую из дат

Водные объекты имеют очень низкий коэффициент отражения в инфракрасной зоне спектра, что позволяет довольно легко выделить их среди прочих элементов местности на снимке, поэтому для дальнейшего исследования использовался соответствующий канал Sentinel-2 (855 - 875 нм). В качестве примера на рис. 5 представлены снимки на 19 и 29 июня.

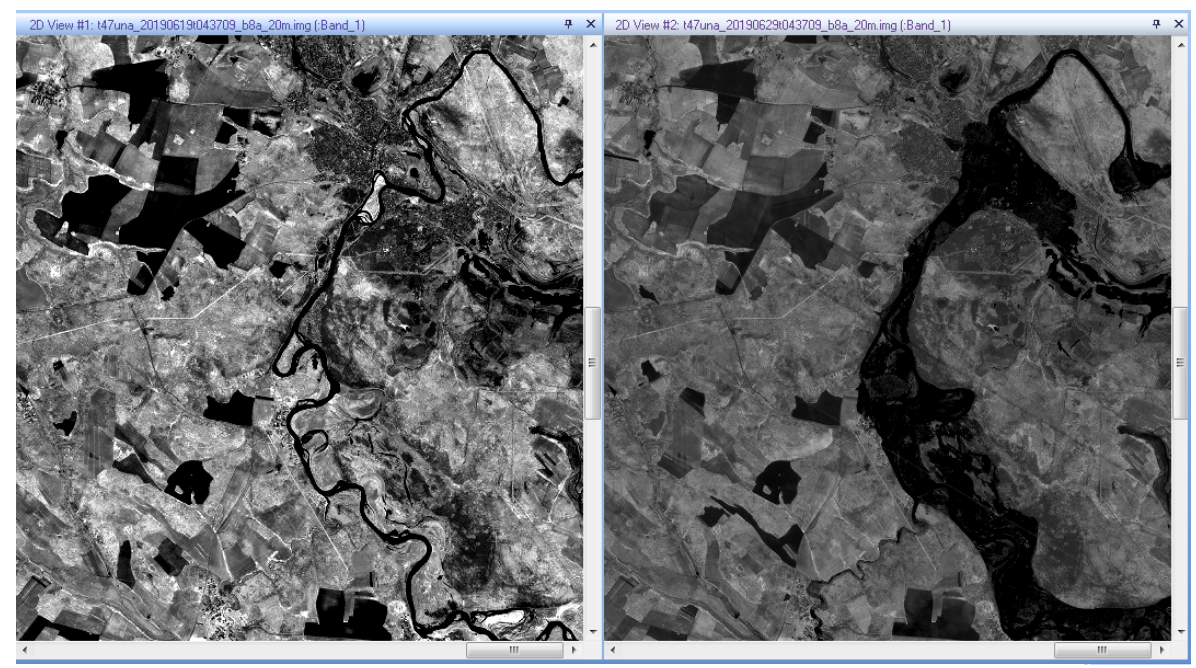

Рис. 5 Снимки на 19 и 29 июня 
Алгоритм выявления изменений позволяет понять, как данная область изменилась между двумя и более периодами времени. Включает в себя сравнение изменений между снимками, сделанными за разные периоды времени, которые охватывают одну и ту же географическую область.

Программный продукт Erdas Imagine обладает встроенным алгоритмом выявления изменений Change Detection. Алгоритмы Change Detection могут использоваться для сопоставления непосредственно разновременных снимков, индексных изображений, результатов направляемой классификации и т. д. В диалоговом окне алгоритма необходимо выбрать Before Image (изображение «до»), After Image (изображение «после»), а также задать имена для Image Difference File и Highlight Change File и пороговые значения изменения яркости (рис. 6).

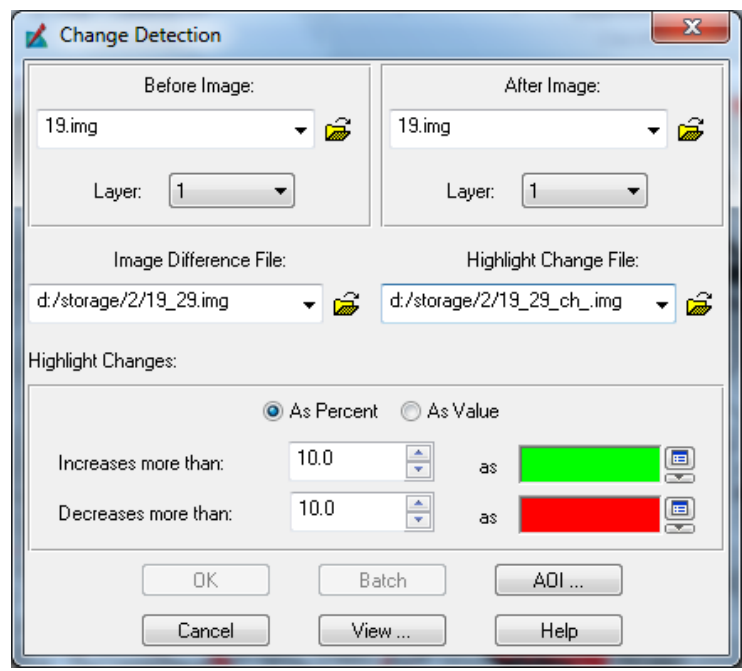

Рис. 6. Диалоговое окно алгоритма Change Detection

На рис. 7 представлена маска зон подтопления, которое произошло в период с 19 по 29 июня 2019 г.

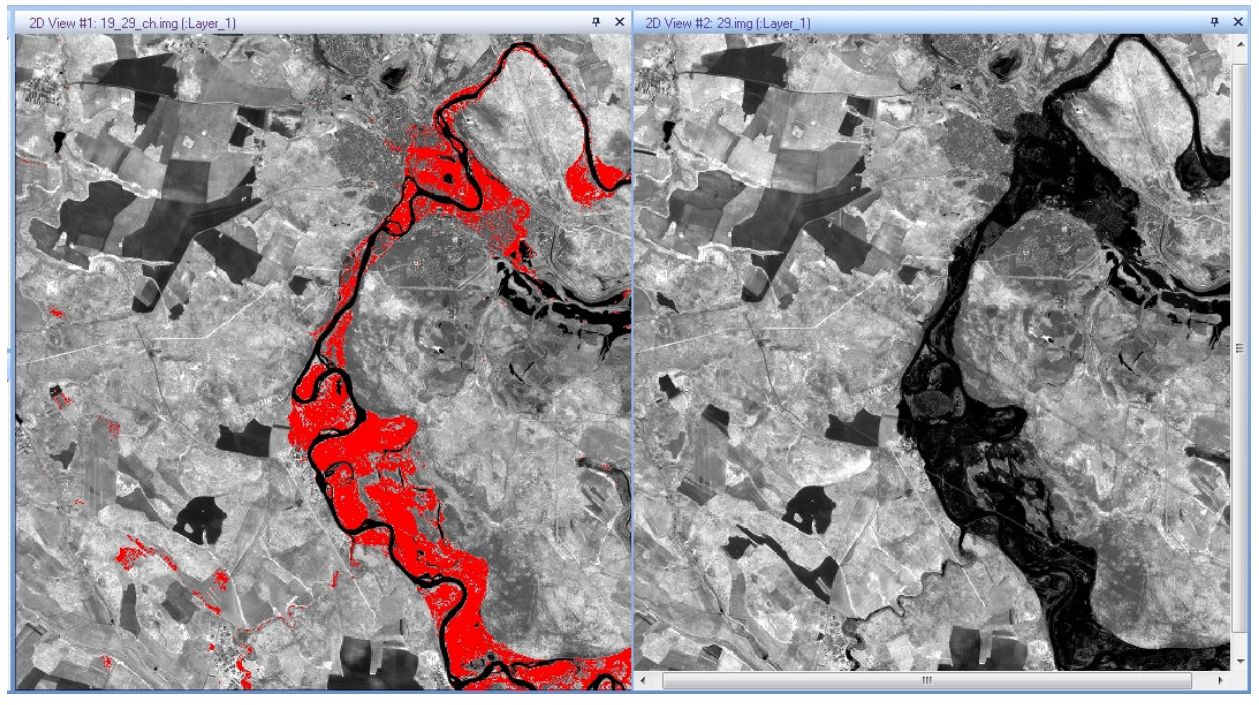

Рис. 7. Маска зон подтопления 
Анализ результатов показывает, что в период с 19 по 29 июня 2019 зона подтопления составила приблизительно 3200 гектар.

\section{Обсуждение}

Таким образом, мониторинг Иркутской области, а именно, города Тулун с помощью программы Erdas Imagine 2015 и снимков, полученных со спутников Sentinel-2, показал, как изменялись площади области подтопления на первую $(19,29$ июня) и вторую волну затопления $(1,4,31$ июля).

\section{Заключение}

В заключении подведем итог, что возможность использования данных дистанционного зондирования при мониторинге водных объектов - разнообразна и в дальнейшем продолжит расширяться. С помощью данных дистанционного зондирования можно получать достоверную информацию о состоянии водных объектов, выявлять и прогнозировать неблагоприятные экологические явления, а также извлекать полезную информацию для составления топографических, тематических карт и т.д.

\section{БИБЛИОГРАФИЧЕСКИЙСПИСОК}

1. Авакян, А. Б. Наводнения / А. Б. Авакян, А. А. Полюшкин. - М.: Знание, 2010. 46 с.;

2. Дворкин, Б. А. Новейшие и перспективные спутники дистанционного зондирования Земли [Текст]: Б. А. Дворкин, С. А. Дудкин // Геоматика. - 2011. - № 4. - С. 26-34.

3. Лагутин, А. А. Дистанционное зондирование Земли из космоса: алгоритмы, технологии, данные [Текст]: учеб.пособие для слушателей молодежной школы семинара / А. А. Лагутин, Р. И. Райкин, Т. Н. Чимитдоржиев. - Барнаул : Изд-во Алт. ун-та, 2013. - 151 с.

4. Михайлов, А. П. Фотограмметрия [Текст]: учебник для вузов / А. П. Михайлов, А. Г. Чибуничев. - М. : МИИГАиК, 2016. -294 с.

5. Наводнение в Иркутской области // ВВС. - 2019. - С. 1-5.

6. Названа сумма ущерба от наводнения в Иркутской области // «Лента.ру». - 2019. - С. 1.

7. Регионы России. Социально-экономические показатели. - 2010: Р32 Стат.сб. М.: Росстат, $2010.996 \mathrm{c}$.

8. Рухович, Д. Применение данных дистанционного зондирования Земли для организации ретроспективного мониторинга земельного покрова [Текст] / Д. Рухович // Земля из космоса. - 2016. - № 5. - C.41-49.

9. Семенов, В. А. Климатически обусловленные изменения опасных и неблагоприятных гидрологических явлений на реках России // Метрология и гидрология. - 2011. - №2. - С. 74-82.

10. Тихонова И. О., Кручинина Н. Е., Десятов А. В. Экологический мониторинг водных объектов : учебное пособие. - : Форум, 2017. - С. 152.

11. Чалов, Р. С. Русловедение: теория, география, практика. Том 2: Морфодинамика речных русел. М.: Красанд, -2011.960 с.

12. Чибуничев, А. Г. Фотограмметрия: вчера, сегодня, завтра [Текст] / А. Г. Чибуничев, А. П. Гук // Изв. вузов. Геодезия и аэрофотосъемка. - 2016. - Т. 60, № 2. - С.3-9.

13. Шаликовский, А. В. Методология управления водохозяйственными рисками, обусловленными экстремальными гидрологическими явлениями // Водное хозяйство России: проблемы, технологии, управление. - 2011. - № 6. - С. 24-32.

14. Шовенгердт Р. А. Дистанционное зондирование. Методы и модели и методы обработки изображений : учебное пособие. - М. : Техносфера, 2013. - 560 с. 
15. Erdas Imagine [Electronic resource], - Mode of Access : https://www.hexagongeospatial.com/products/power-portfolio/erdas-imagine.

16. Erdas Imagine 2015 // vseprogi.com. - 2019. - C. 1;

17. Monitoring and assessing water quality [Electronic resource], - Mode of Access : https://www.water.wa.gov.au/water-topics/water-quality/monitoring-and-assessing-water-quality.

18. Sentinel-2 [Electronic resource], - Mode of Access : https://sentinel.esa.int/web/sentinel/missions/sentinel-2.

19. Sentinel-2A, 2B // ГК «Иннотер». - 2019. - С. 1.

20. What is remote sensing? [Electronic resource], - Mode of Access : https://earthdata.nasa.gov/learn/remote-sensing.

(C) Н. С. Решетило, Е. П. Хлебникова, 2021 